\title{
Literature Review of Experimental Study on Load Bearing Masonry Wall
}

\author{
Mir Abdul Kuddus ${ }^{1 *}$, Pere Roca Fabregat ${ }^{2}$ \\ ${ }^{1}$ Assistant Professor, Department of Civil Engineering, Khulna University of Engineering \&Technology, \\ Khulna-9203, Bangladesh, \\ ${ }^{2}$ Professor, Department of Civil and Construction Engineering, Technical University of Catalonia, Barcelona- \\ 08034, Spain.
}

\begin{abstract}
Masonry load bearing wall subjected to vertical concentric and eccentric loading may collapse through instability. In this Paper the buckling behavior of masonry load bearing wall of different slenderness ratio were investigated by many researcher has been reviewed via testing a series of scale masonry wall subjected to concentric and eccentric vertical loading. The influence of nonlinear behavior of interface element, slenderness ratio and various end conditions have been investigated together with the effect of different end eccentricity of vertical load.
\end{abstract}

Keywords: Masonry load bearing wall, buckling failure, eccentric load, slenderness ratio.

\section{Introduction}

Historically, the structural design of masonry buildings was based on the empirical requirements of building codes for minimum wall thickness and maximum height. Bearing wall construction for buildings higher than three to five stories was uneconomical and other methods of support (steel or concrete skeleton frame) were generally used. In 1965, there was a renewed interest on the part of the design professional, architect and engineer, in modern bearing wall construction, wherein the design is based on a rational structural analysis rather than on outmoded arbitrary requirements. Many research projects have been conducted on the properties of the three basic components and the overall unreinforced masonry wall with vertical load and load eccentricities. The literature on the subject shows large number of studies carried out on axially loaded walls with varying slenderness ratio. Among the first, Chapman and Slatford (1957) obtained closed form solutions for the load deformation behaviour of brittle elastic wall by assuming that masonry material has no tensile strength and that cracking occurs whenever a tensile stress would develop. After that Yokel's (1971) results on the buckling of walls made of no-tension material are well known. De Falco's proposal (2002) on the stability of columns using an elastic-plastic material model stands among the most recently presented analytical approaches. More recently, Mura (2008) has utilized a parabolic stress-strain relationship to describe the behaviour of the brickwork under compression loads. Shalin (1978) reviewed the results of analysis carried out by a number of authors and presented experimental evidence in support of the calculations. Further work was carried out by Sawko and Towler (1982) who proposed a numerical procedure for calculating the failure load of a no-tension material wall. An analytical solution has been carried out by Romano et al. (1993), considering no tension bearing masonry with a monomial stress-strain relationship in compression. Parland et al. (1982) proposed a method for determining buckling failure load of a slender wall, taking into account the effect of tension stress field which exists between the cracked joints. However, the linear elastic materials were used in this analysis.

\section{Review of Experimental Test of Masonry Walls under Concentric and Eccentric Loading}

In this section a review of previous experimental tests in order to study the bearing capacity of masonry walls under the combined effect of slenderness and eccentricity the load has been discussed. Specifically, the experimental tests carried out by Kirtschig and Anstotz(1991), Watstein and Allen (1971) and Hasan and Hendry (1976) has described. The review of these studies will focus on these experimental techniques, objectives, results and conclusions.

\subsection{Kirtschig and Anstotz (1991)}

The influence of slenderness ratio and eccentricity of the load on the load bearing capacity of the masonry is subjected to different treatments in the regulations of each country. The main objective of the experimental tests developed by Kirtschig and Anstotz (1991) was to verify this overestimation by comparing load bearing capacity values with theoretically derived results. The experimental development proposed an empirical formula for the calculation of capacity reduction factors for any eccentricity and slenderness ration under vertical load by using: 
$\alpha=\frac{E}{4 f_{m a}}$

The masonry units considered for the test were calcium silicate and lightweight aggregate concrete with average compressive strength of the units $20.9 \mathrm{MPa}$ and $4.1 \mathrm{MPa}$ respectively. For the specimens mortar with a compressive strength of about $5 \mathrm{MPa}$ was used. The length of the walls was about $1 \mathrm{~m}$ and a thickness of $11.5 \mathrm{~cm}$. In order to introduce the study with different slenderness ratio, walls were made of different heights. These heights were $63.5 \mathrm{~cm}, 125 \mathrm{~cm}, 212 \mathrm{~cm}$ and $312 \mathrm{~cm}$, which translates into approximately slenderness ratio(calculated as ratio between height and thickness) of 5.6, 11.1, 18.8 and 27.7. A total of 64 walls were tested (32 for each type of wall). The test arrangement of the walls in this way that free rotation on top and bottom was possible (shown in figure 1). The results obtained in the experimental test are shown in Tables 1 and 2 and represented graphically in Figures 2 and 3.
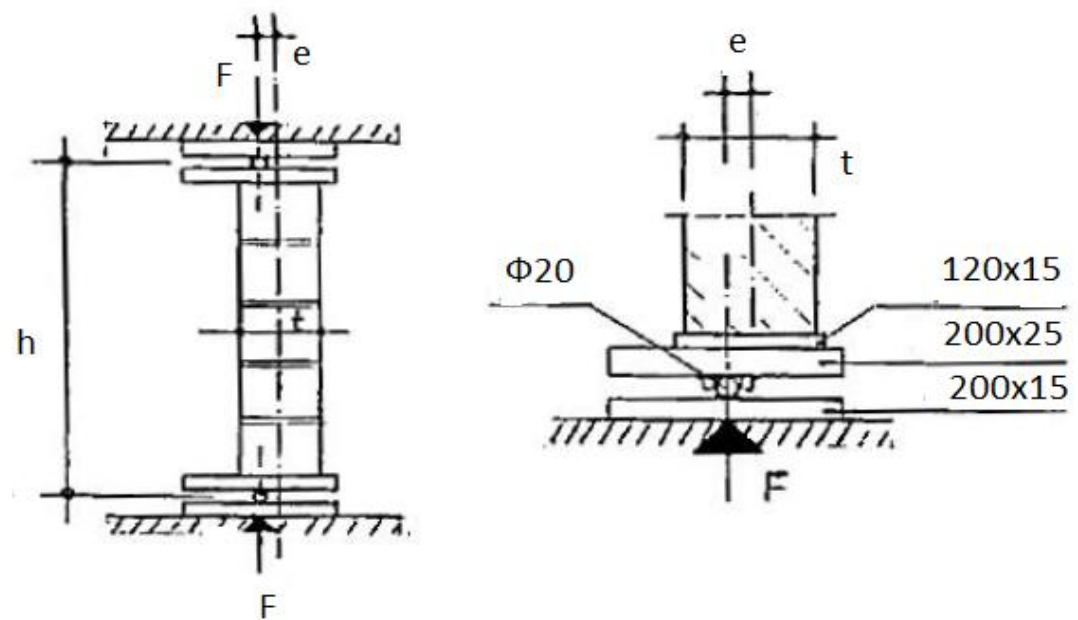

Figure 1: Arrangement of walls for testing (Kirtschig and Anstotz, 1991).

Table 1: Test results in the case of calcium silicate units (Kirtschig and Anstotz, 1991).

\begin{tabular}{|l|l|l|l|l|}
\hline $\begin{array}{l}\text { Slenderness ratio } \\
(\mathrm{h} / \mathrm{t})\end{array}$ & \multicolumn{4}{|l|}{ Failure load (KN) (1-means individual and 2-means mean results) } \\
\hline & $\mathrm{e}=0$ & $\mathrm{e}=\mathrm{t} / 8$ & $\mathrm{e}=\mathrm{t} / 4$ & $\mathrm{e}=\mathrm{t} / 3$ \\
\hline 5.6 & $1450(1)$ & 1050 & 685 & 328 \\
& $1350(1)$ & 950 & 585 & 382 \\
\cline { 2 - 5 } & $1400(2)$ & 1000 & 635 & 355 \\
\hline \multirow{5}{*}{5.1} & 1225 & 900 & 100 & 170 \\
& 1270 & 860 & 465 & 144 \\
\cline { 2 - 5 } & 1248 & 880 & 433 & 157 \\
\hline \multirow{3}{*}{18.8} & 1170 & 460 & 214 & 138 \\
& 1060 & 600 & 204 & 118 \\
\cline { 2 - 5 } & 1115 & 530 & 209 & 128 \\
\hline 27.7 & 710 & 240 & 80 & 35 \\
& 615 & 270 & 84 & 32 \\
\cline { 2 - 5 } & 663 & 255 & 82 & 34 \\
\hline
\end{tabular}

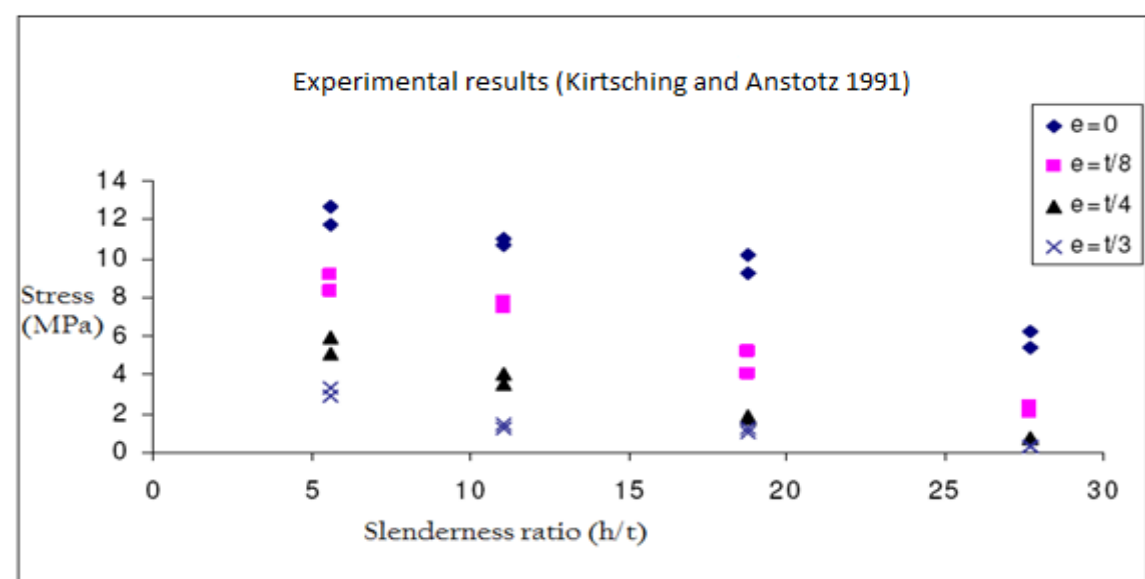

Figure 2: Test results in the case of calcium silicate units (Kirtschig and Anstotz, 1991). 
Table 2: Test results in the case of lightweight concrete units (Kirtschig and Anstotz, 1991).

\begin{tabular}{|l|l|l|l|l|}
\hline $\begin{array}{l}\text { Slenderness ratio } \\
(\mathrm{h} / \mathrm{t})\end{array}$ & \multicolumn{4}{|l|}{ Failure load (KN) (1-means individual and 2-means mean results) } \\
\hline & $\mathrm{e}=0$ & $\mathrm{e}=\mathrm{t} / 8$ & $\mathrm{e}=\mathrm{t} / 4$ & $\mathrm{e}=\mathrm{t} / 3$ \\
\hline \multirow{5}{*}{5.6} & $395(1)$ & 280 & 185 & 138 \\
& $368(1)$ & 310 & 175 & 130 \\
\cline { 2 - 5 } & $382(2)$ & 295 & 180 & 134 \\
\hline \multirow{3}{*}{11.1} & 390 & 265 & 132 & 80 \\
& 332 & 280 & 150 & 78 \\
\cline { 2 - 5 } & 361 & 273 & 141 & 79 \\
\hline \multirow{3}{*}{18.8} & 302 & 208 & 90 & 60 \\
& 350 & 162 & 96 & 51 \\
\cline { 2 - 5 } & 326 & 185 & 93 & 36 \\
\hline 27.7 & 248 & 116 & 64 & 36 \\
& 210 & 110 & 60 & 33 \\
\cline { 2 - 5 } & 229 & 113 & 62 & \\
\hline
\end{tabular}

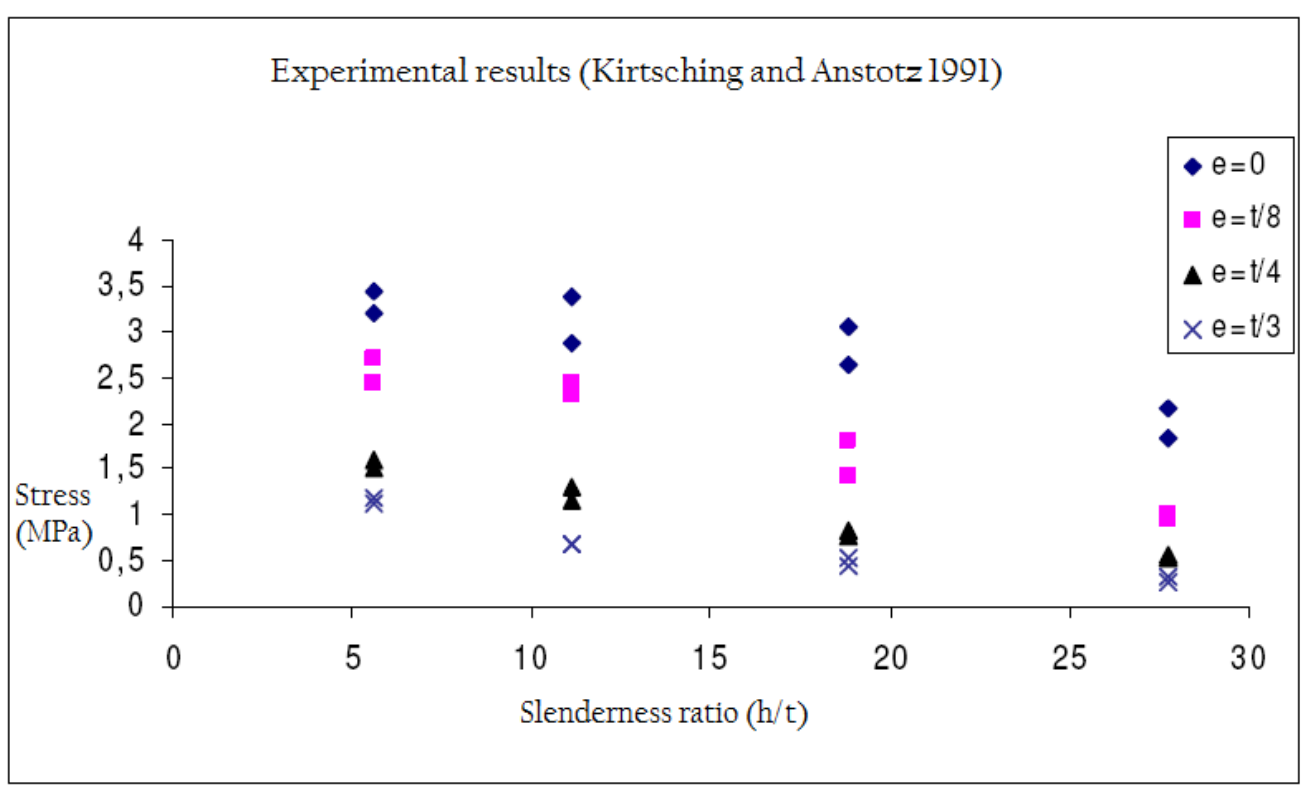

Figure 3: Test results in the case of lightweight concrete units (Kirtschig and Anstotz, 1991).

The comparison established by Kirtschig and Anstotz (1991) shows a greater proximity between the experimental and theoretical values, which led them to assert that development is a good approach for determining the bearing capacity of the masonry face action vertical loads with the advantage of being a relatively simple expression management.

\subsection{Watstein and Allen (1970)}

The main factor of limiting the strength of brick masonry imposed by the relatively low tensile bond strengths developed between the masonry units and conventional Portland cement mortars. According to the authors, the mechanism of failure due to geometric instability of the masonry works suggests that increasing of bond tensile strength of masonry will significantly affect not only the transverse strength of the masonry but also its compressive and shearing strengths. The typical mode of failure in compression is neither crushing nor shear, but tensile splitting of the materials as a result of axial loading. The walls were tested as hinged-hinged compression members, centrally supported at the bottom. The arrangement of testing is shown in the Figure 4. The applied load eccentricity were $0, t / 6$ and $t / 3$. Six type brick were used in the test of compressive prism to investigate the effect of brick compressive strength on the compressive strength of masonry. The mortar was prepared from type I Portland cement, hydrated lime and sand mixed with marble dust as additive and organic modifier saran polymer. 


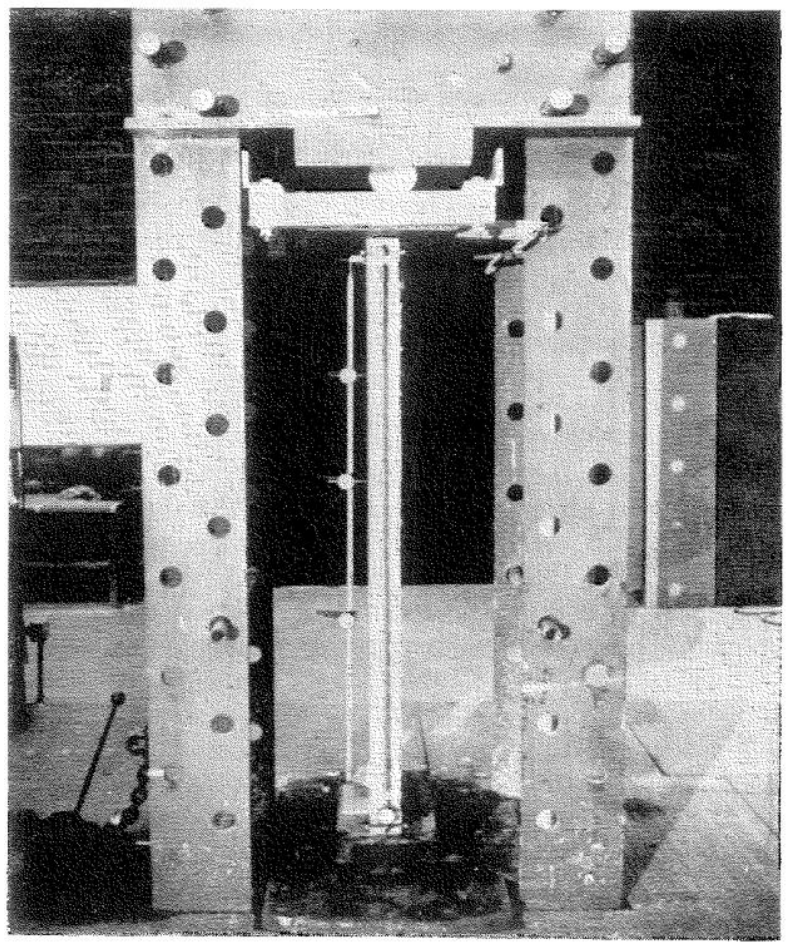

Figure 4: View of an eccentrically loaded wall in testing machine (Watstein and Allen, 1971).

The effect, slenderness ratio and the eccentricity of applied load, was studied for walls built with high bond mortar ranging in height from 37 inch to 144 inch with effective slenderness ratio 12.4, 22.8, 32 and 42.5 . The capacity obtained for the walls with mortar of high adhesion according to slenderness ratio and comparing these capacity values with walls of conventional mortar walls are reflected in Figures 5 and 6.

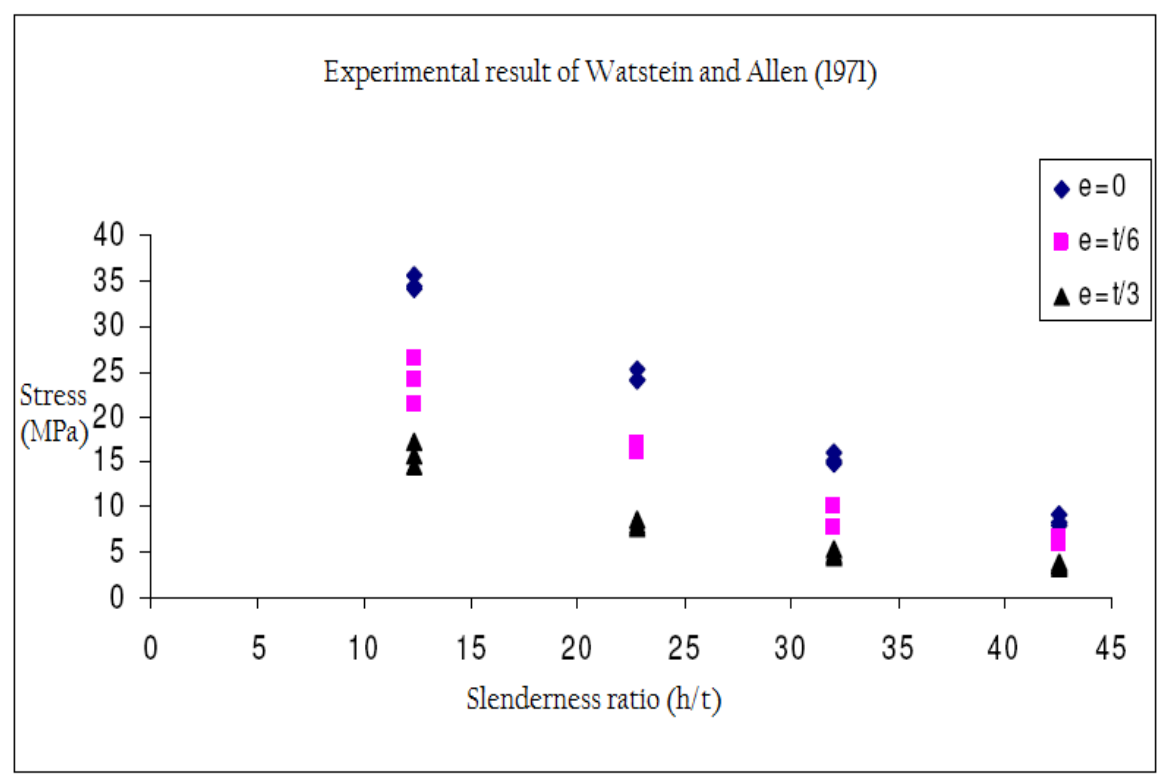

Figure 5: Capacity of walls obtained with mortar of high strength for different slenderness and load eccentricity (Watstein and Allen, 1971).

Comparing the strength obtained for the effective slenderness ratio 22.8 shows that the capacity of walls with high bond mortar is was $1.09,1.25$ and 1.33 times of the capacity of conventional type mortar walls for the eccentricity ratio of $0,1 / 6$ and $1 / 3$ respectively. From the results it is clear that performance of high bond mortar walls compared to conventional mortar increases with eccentricity of load application. This is because a higher eccentricity applied the greater the influence of tensile strength developed in the joints. 


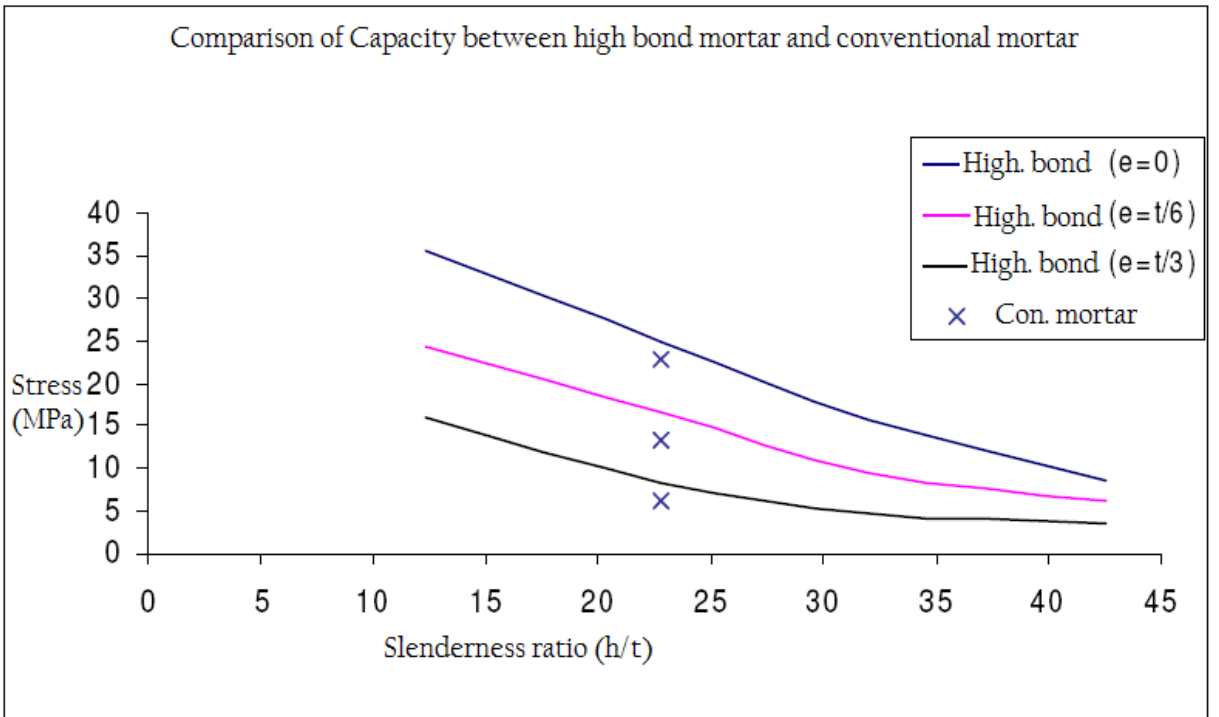

Figure 6: Relationship between the average compressive strength of the walls and the value of its slenderness ratio for different load eccentricity (Watstein and Allen, 1971).

The compressive strength of walls built with mortar high adhesion of slenderness ratio 22.8 was $25 \%$ greater than the resistance of walls made of conventional mortar for eccentricity equal to one sixth the thickness of the wall. For the eccentricity equal to one third the thickness of the wall, compressive strength of high bond mortar walls was $33 \%$ greater than the strength of walls with conventional mortar. In these data reflected the influence of the tensile strength of the wall is greater in the case of the greater eccentricity of load application because the lateral deflections given for the same load value increases with eccentricity.

\subsection{Hasan and Hendry (1976)}

The effect of slenderness ratio and eccentricity on the compressive strength of wall was investigated by Hasan and Hendry (1976). The main objective of this study was to determine whether reduction factors prescribed in various codes are conservatives. One third scale model has been tested with axial and eccentric loading and with various end conditions. The arrangement for rotation measurement is shown in the Figure 7. The results were compared with various national codes. Twenty five specimens were tested for various slenderness ratio 6, 12, 18 and 25 with different end conditions (flat ended, reinforced concrete slab and hinged) and load eccentricity of $0, \mathrm{t} / 6$ and $\mathrm{t} / 3$.

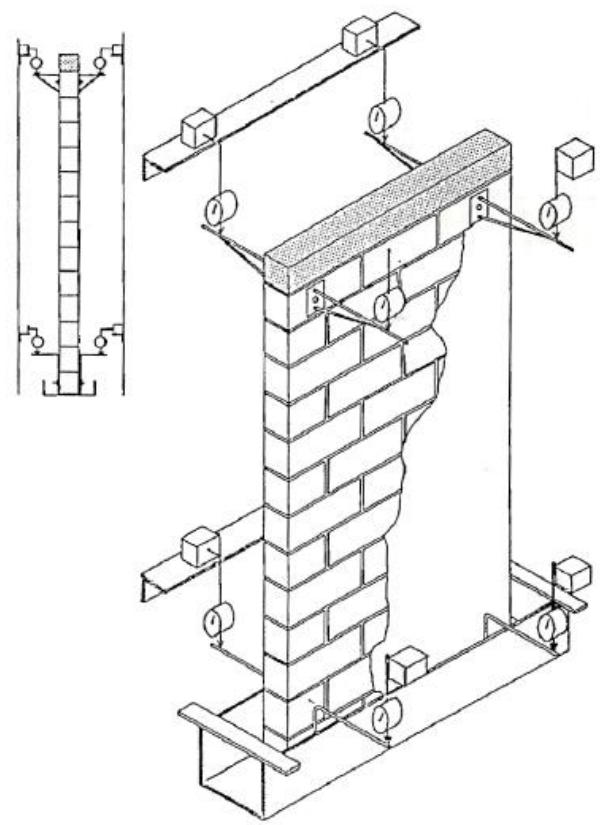

Figure 7: Test setting for measurement of rotation at the supports (Hasan and Hendry, 1976). 
One third scale solid bricks were used with variable strength. For calculation purpose the strength of brick unit was taken as $\mathrm{f}_{\mathrm{b}}=28 \mathrm{MPa}$. Dry Leighton buzzard sand with rapid hardening Portland cement was used for all tests. The water cement ratio for mortar varied from 0.8 to 0.95 . The results of the test carried out by the author's reflected in the Figure 8. In all walls except hinge supported series, the first hairline crack appeared between $50-60 \%$ of failure load and enlarged with further increase of load. The general mode of failure of the walls was vertical splitting accompanied by crushing and splitting of various courses of bricks. However, in walls of slenderness ratio 25 and all walls of vertical load eccentricity $t / 3$ group failure occurred at mortar brick interface due to breakdown of bond between the mortar and the brick at the time of maximum deflection.

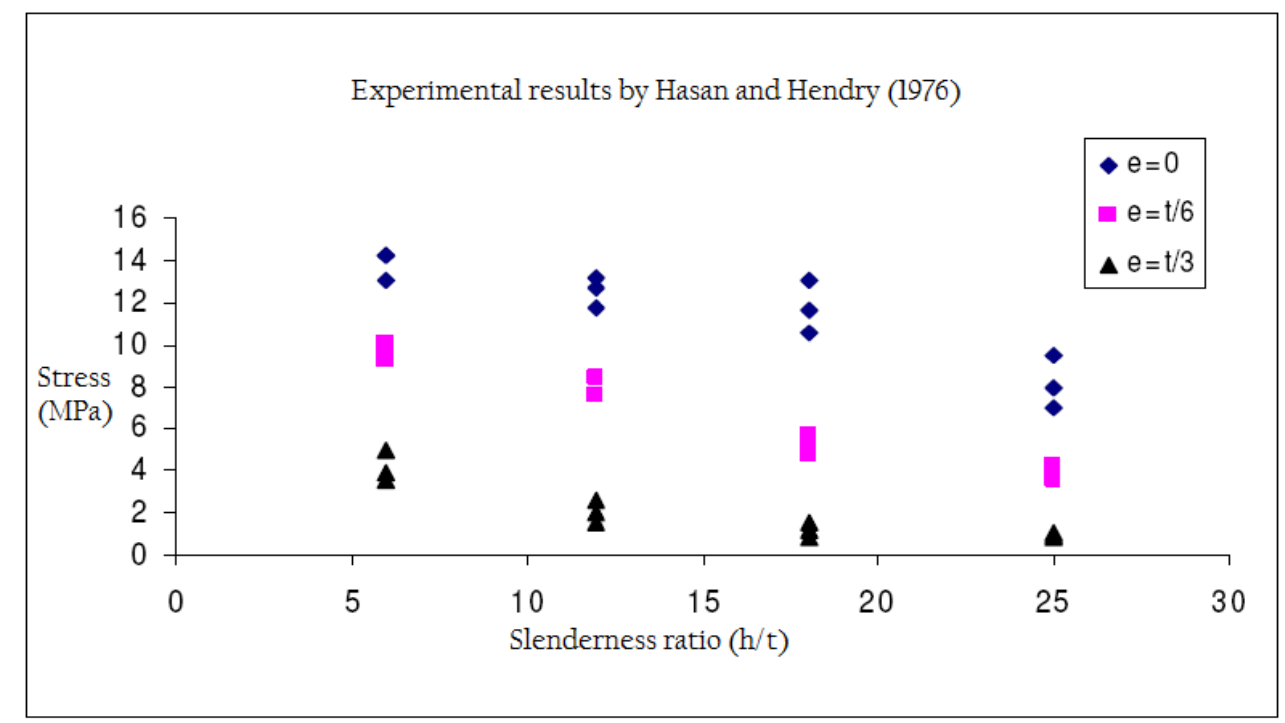

Figure 8: Relation between the capacity of walls and slenderness ratio with various eccentricity (Hasan and Hendry, 1976).

When comparing the reduction factor calculated by the author's found that except the walls with slenderness ratio 25 , the reduction factor calculated according to SCP1 is about $10 \%$ lower in the series of hinge supported walls with eccentricity 0 . In the case of walls series eccentrically loaded $t / 6$, the reduction factor obtained is practically same as that obtained by SCP1. However, the value of reduction factor for wall series eccentrically loaded at $\mathrm{t} / 3$ is $25 \%$ higher than SCP1. It is noteworthy that the maximum value of the slenderness of the walls tested by the authors is 25.0 , while the results of SCP1 provide up to 46.1 slenderness ratio.In the opinion of the authors, test walls with slenderness greater than 30 are more a matter of academic rather than practical interest. The results of Haller (1969) are approximately $18 \%$ lower than those obtained by the authors for the series walls with 0 eccentricities. In the case of walls of applied load with an eccentricity equal to one sixth of wall thickness, the results of Haller are lower than those obtained by the authors.

\section{Conclusions}

The diverse combinations of slenderness ratio and load eccentricity used in the experimental program which provided the means for a comprehensive numerical analysis of the masonry wall. It must be noted that some difference with respect to the experimental results is unavoidable because of the influence of possible nonreported accidental eccentricities. It has been observed that an accurate description of tensile cracking and opening of mortar joints, by means of an appropriate interface element, is essential to obtain reliable results on the bucking failure of walls.

\section{Acknowledgements}

In completing this research, I would like to express my grateful appreciation and special thanks to Professor Paulo Lourenco, Professor Enrico Garbin and PhD student Cristian Sandoval. A financial support from European Commission through Erasmus Mundus Scholarship is gratefully acknowledged.

\section{References}

[1]. Chapman, J. C. and Slatford, J. (1957). “The Elastic Buckling of Brittle Columns.” Inst. Civ. Eng., Vol. 107, No. 6.

[2]. De Falco, A. and Lucchesi, M. (2007). "No Tension Beam-Columns with Bounded Compressive Strength and Deformability Undergoing Eccentric Vertical Loads.” International Journal of Mechanical Sciences 49, p. 54-74.

[3]. Hasan, S. S. and Hendry, A.W. (1976). "Effect of Slenderness and Eccentricity on the Compressive Strength of Walls." Proc. $4^{\text {th }}$ International Brick Masonry Conference (Brugge). Paper 4.d3. 
[4]. KIRTSCHIG, K. and ANSTOTZ, W. (1991) - Kinckuntersuchungen an mauerwerksproben. Proceedings of $9^{\text {th }}$ International brick/block masonry Conference, p. 202-209.

[5]. Lourenco, P. B. (1996). "Computational Strategies for Masonry Structures." PhD thesis, Delft University of Technology, Delft, The Netherlands.

[6]. Mura, I. (2008). "Stability of Nonlinear Masonry Members Under Combined Load." Computers and Structures 86, p. $1579-1593$.

[7]. Page, A.W. (1978). "Finite Element Model for Masonry." J. Struc. Div., ASCE, 104(8), p. 1267-1285.

[8]. Parland, H. (1982). "Basic Principles of the Structural Mechanics of Masonry: A Historical Review.” Int. J. Mas. Constr., 2(2).

[9]. Payne, D. C., Brooks, D. S. and Dved, G. (1990). "The Analysis and Design of Slender Brick Walls." Masonry International Journal, 4(2), p. 55-65

[10]. Pluijm, R. V (1992). "Material Properties of Masonry and its Components Under Tension and Shear.” Proc. 6th Canadian Masonry Symposium, Eds. V.V. Neis, Saskatoon, Saskatchewan, Canada, p. 675-686.

[11]. Sahlin, S. (1978). "Structural Masonry." Prentice-Hall Inc., New jersey, U. S. A.

[12]. Sawko, F. and Towler, F. (1982). "Numerical Analysis of Walls and Piers with Different End Conditions." 6IBMAC. Ed. Laterconsult s.v.l., Rome, Italy.

[13]. WATSTEIN, D. and ALLEN, M. H. (1970) - Structural performance of clay masonry assemblages built with high-bond organicmodified mortars. SIBMAC Proceedings, Ed. H.W.H. West and K.H. Speed, p.99-112.

[14]. Yokel, F. Y. (1971). "Stability and Load Capacity of Members with no Tensile Strength.” J. Struct. Div. ASCE, 97(7), p. 19131926. 